\title{
Provenance variation in growth and genetic potential of Aquilaria malaccensis under nursery condition
}

\author{
M. B. Noor Mohamed ${ }^{\star}$, K. T. Parthiban, R. Ravi and P. Kumar \\ Forest College and Research Institute, Tamil Nadu Agricultural University, Mettupalayam, Tamil Nadu, 641301 , India.
}

Received 11 November, 2013; Accepted 15 June, 2015

\begin{abstract}
Aquilaria malaccensis Lam. is commonly known as Agarwood which is distributed in the Indo-malesian genus Aquilaria of family Thymelaeaceae known to produce resin-impregnated heartwood that is fragrant and highly valuable. Agarwood is reputed to be the most expensive wood in the world. Twenty two open pollinated families in $A$. malaccensis were selected and evaluated for growth attributes and genetic divergence. The experiment was conducted at Forest College and Research Institute, Tamil Nadu Agricultural University; Mettupalayam situated at $11^{\circ} 19^{\prime} \mathrm{N}$ longitude, $76^{\circ} 56^{\prime}$ E latitude at $300 \mathrm{MSL}$ during January - December 2010. The study indicates significant differences among the selected families for various growth attributes. Among the twenty two progenies evaluated, three progenies viz., NHJA, KHOW-1 and CHEK-1 exhibited consistent superiority over growth periods for shoot length, collar diameter and number of branches. Genetic divergence studies resulted in grouping of the selected families into six clusters which indicated the existence of adequate genetic divergence. Among the clusters, cluster VI was the largest with 9 progenies while the maximum intra clusters distance was recorded in cluster $V$. The intra and inter cluster distance revealed that maximum inter cluster distance was recorded between cluster IV and V which indicated the presence of wide genetic distance between A. malaccensis progenies. Among the various growth attributes, number of branches contributed maximum towards genetic divergence followed by shoot length. These two characters could act as a reliable indicator for future improvement programme in this economically important species. Genetic analysis of the progenies indicated adequate variability in the population. The phenotypic co-efficient of variation (PCV) and genotypic co-efficient of variation (GCV) estimates exhibited superiority of number of branches followed by shoot length and collar diameter. In case of shoot length, collar diameter and number of branches exhibited moderate heritability. The genetic advance was high for shoot length followed by number of branches which indicated the reliability of these two parameters for inclusion in future improvement programme.
\end{abstract}

Key words: Aquilaria malaccensis, provenances, variability, heritability, genetic divergence, intra and inter cluster distance.

\section{INTRODUCTION}

Aquilaria malaccensis Lam. is one of the 15 tree species in the Indomalesian genus Aquilaria of family Thymelaeaceae and eight are known to produce resinimpregnated heartwood that is fragrant and highly valuable ( $\mathrm{Ng}$ et al., 1997). There are many names for this resinous wood, including agar, agarwood, aloe(s) wood, eaglewood, gaharu and kalamabak. This wood is in high demand for medicine, incense and perfume across Asia 
and the Middle East. The tree grows in natural forests at an altitude of a few meters above sea level to about 1000 $\mathrm{m}$, and it grows best around $500 \mathrm{~m}$ in locations with average daily temperatures of 20 to $22^{\circ} \mathrm{C}$ (Afifi, 1995; Keller and Sidiyasa, 1994; Wiriadinata, 1995). Aquilaria $\mathrm{sp}$. has adapted to live in various habitats, including those that are rocky, sandy or calcareous, well-drained slopes and ridges and land near swamps. It is a large evergreen tree, growing over 15 to $40 \mathrm{~m}$ tall and 0.6 to $2.5 \mathrm{~m}$ in diameter, and has white flowers (Chakrabarty et al., 1994; Sumadiwangsa, 1997). The 2002 IUCN Red List classifies this species as vulnerable. A. malaccensis occurs mostly in the foothills of the North-eastern region (Assam, Meghalaya, Nagaland, Mizoram, Manipur, Arunachal Pradesh and Tripura) and West Bengal up to an altitude of $1000 \mathrm{~m}$. In Assam and Meghalaya, it occurs sporadically in the district of Sibsagar, Sadiya, Nowgong, Darrang, Goalpara, Garo Hills and Cachar (Atal and Kapoor, 1982). A report by Chakrabarty et al. (1994) documenting India's trade in agarwood concluded that $A$. malaccensis is highly threatened in that country due to exploitation of the species for commercial purposes. $A$. malaccensis is threatened in its natural habitat because of overexploitation.

Demand for agarwood has resulted in the unsustainable harvesting of the species, leading to local extinctions. Wild agarwood was heavily extracted from Arunachal Pradesh between the late 1950s and the early 1980 s, virtually exhausting the natural stock. Wild $A$. malaccensis is now considered almost extinct in Assam. Surveys undertaken by the Regional CITES Management Authority in Tripura indicate that the natural stock is almost exhausted in that State as well. In Mizoram, the lack of agarwood plantations in Mizoram and Meghalaya has resulted in much illegal harvesting from natural forests. A. malaccensis in Nagaland and Manipur is so depleted that a large proportion of the raw agarwood used by processing units in these two States is sourced from neighbouring countries. Because of its vast natural distribution and the diversity of ecological conditions where the species occurs, $A$. malaccensis would be expected to have considerable genetic variation (Shivkumar and Banerjee, 1986). Knowledge of variability within a species is a prerequisite for developing effective tree improvement / breeding strategies (Vakshasya et al., 1992). The significance of genetic variation studies and provenance testing in forest tree improvement is well realized.

Success in the establishment and productivity of forest tree plantations is governed largely by the species used and the source of seed within species (Larsen, 1954; Lacaze, 1978). No matter how sophisticated the breeding techniques, the largest, cheapest and fastest gains in most forest tree improvement programs will accrue if use of suitable species and seed sources within species is assured (Zobel and Talbert, 1984). Provenance research is therefore of paramount importance. Provenance is defined as a subdivision of species consisting of genetically similar individuals, related by common descent and occupying a particular territory to which it has become adapted through natural selection.

Therefore, present investigation has been carried out to estimate genetic variation present in $A$. malaccensis populations and survival percentage of species at Forest college and Research institute, Mettupalayam, Tamil Nadu.

\section{MATERIALS AND METHODS}

\section{Selection of superior genetic resource}

The survey has been conducted in predominant $A$. malaccansis growing areas of India and twenty two different provenances from North-Eastern states of Assam (6), Tripura (10) and Nagaland (6) were selected. Based on morphological characters such as diameter, height, number of branches and clear bole height of superior Agar wood, genetic resources were selected and measurement were recorded as given in the Table 1.

\section{Geographical location of the population}

Six provenances from Assam (MDLY, UDLY-1, UDLY-2, NHJA, $\mathrm{NHSU}$, and $\mathrm{HAKH}$ ), Ten Provenances from the state of Tripura (KHOW-1, KHOW-2, AMBS, CENT-1, CENT-2, KUMA-R, KUMA, FUKO, KUMA-RO, ROWA) and six provenances (DI-FC, DI-TY, DIPU, CHEK-1, CHEK-2, CHEK-3) from Nagaland were used for this study. Geographic locations, altitude, locations of twenty two different provenances were seeds are collected for study are cited in Table 2.

\section{Experimental site description}

The experiment was conducted at Forest College and Research Institute, Tamil Nadu Agricultural University, Mettupalayam situated at $11^{\circ} 19^{\prime} \mathrm{N}$ longitude and $76^{\circ} 56^{\prime} \mathrm{E}$ latitude at $300 \mathrm{msL}$ during January to July 2013. The experimental site receives an annual rainfall of $800 \mathrm{~mm} /$ annum with the maximum and minimum temperature of 33.8 and $21.2^{\circ} \mathrm{C}$, respectively. The soil is predominantly red lateritic with a $\mathrm{pH}$ of 7.1 .

\section{Nursery technique and seedling establishment of each provenance}

Pretreated seeds were directly sown in polythene bags $(20 \times 40 \mathrm{~cm}$ size) containing potting mixture of sand, soil and farmyard manure in the ratio of 2:1:1 and watered regularly as and when required.

\section{Experimental design and treatment}

The nursery experimental trail was laid out using a Completely 
Table 1. Morphological characters of superior genetic resources of Agar wood.

\begin{tabular}{cllcccc}
\hline S/N & $\begin{array}{l}\text { Provenance } \\
\text { name }\end{array}$ & Location & GBH (cm) & Height (m) & $\begin{array}{c}\text { Clear bole } \\
\text { Height }(\mathbf{m})\end{array}$ & $\begin{array}{c}\text { Number of } \\
\text { Branches }\end{array}$ \\
\hline 1 & MDLY & Modhertally & 52.20 & 7.50 & 4.50 & 16 \\
2 & UDLI-1 & Udali-1 & 68.00 & 16.5 & 4.00 & 20 \\
3 & UDLI-2 & Udali-2 & 70.00 & 14.0 & 5.00 & 20 \\
4 & NHJA & Nahaurani-Jangoan village & 89.00 & 19.5 & 9.00 & 21 \\
5 & NHSU & Nahaurani- Sumoni & 81.00 & 19.0 & 5.00 & 17 \\
6 & HAKH & Hatiekhowa village & 79.00 & 17.5 & 6.50 & 18 \\
7 & KHOW-1 & Khowai-1 & 103.0 & 18.5 & 7.00 & 22 \\
8 & KHOW-2 & Khowai-2 & 100.0 & 19.0 & 7.50 & 20 \\
9 & AMBS & Ambassa & 390.0 & 27.0 & 7.00 & 52 \\
10 & CENT-1 & Central nursery-1 & 110.0 & 18.0 & 12.0 & 10 \\
11 & CENT-2 & Central nursery-2 & 127.0 & 22.0 & 11.0 & 17 \\
12 & KUMA-R & Kumargath-RFO house & 147.0 & 25.0 & 10.0 & 18 \\
13 & KUMA & Kumargath & 88.00 & 18.0 & 7.00 & 22 \\
14 & FUKO & Fukirkohi & 87.00 & 16.0 & 2.00 & 18 \\
15 & KUMA-RO & Kumargath-range office & 230.0 & 28.0 & 3.80 & 96 \\
16 & ROWA & Rowa & 81.00 & 13.0 & 3.00 & 15 \\
17 & DI-FC & Dimapur-Forest colony & 72.00 & 16.5 & 4.00 & 16 \\
18 & DI-TY & Dimapur- Tykho village & 58.00 & 12.0 & 6.00 & 18 \\
19 & DIPU & Diphupur & 72.00 & 17.5 & 7.50 & 16 \\
20 & CHEK-1 & Chekieye village-1 & 87.00 & 18.0 & 6.50 & 24 \\
21 & CHEK-2 & Chekiye village-2 & 75.00 & 17.0 & 7.00 & 17 \\
22 & CHEK-3 & Chekiye village-2 & 83.00 & 16.5 & 7.00 & 18 \\
\hline
\end{tabular}

Table 2. Details of location, latitude, longitude, elevation $(\mathrm{m})$ of superior genetic resources of Agar wood provenance.

\begin{tabular}{clllllc}
\hline S/N & Provenance name & Location & State & Latitude & Longitude & Elevation $(\mathbf{m})$ \\
\hline 1 & MDLY & Modhertally & Assam & $26^{0} 08.100$ & $92^{0} 49.771$ & 123 \\
2 & UDLI-1 & Udali-1 & Assam & $25^{0} 53.304$ & $93^{0} 00.604$ & 89 \\
3 & UDLI-2 & Udali-2 & Assam & $25^{0} 53.303$ & $93^{0} 00.600$ & 90 \\
4 & NHJA & Nahaurani-Jangoan village & Assam & $26^{0} 38.856$ & $94^{0} 03.318$ & 80 \\
5 & NHSU & Nahaurani- Sumoni & Assam & $26^{0} 38844$ & $94^{0} 03.348$ & 78 \\
6 & HAKH & Hatiekhowa village & Assam & $26^{0} 36.476$ & $94^{0} 01.826$ & 82 \\
7 & KHOW-1 & Khowai-1 & Tripura & $24^{0} 04.186$ & $91^{0} 36.868$ & 40 \\
8 & KHOW-2 & Khowai-2 & Tripura & $24^{0} 06.170$ & $91^{0} 36.840$ & 47 \\
9 & AMBS & Ambassa & Tripura & $23^{0} 55.138$ & $91^{0} 50.522$ & 74 \\
10 & CENT-1 & Central nursery-1 & Tripura & $23^{0} 54.891$ & $91^{0} 53.144$ & 115 \\
11 & CENT-2 & Central nursery-2 & Tripura & $23^{0} 54.927$ & $91^{0} 53.175$ & 126 \\
12 & KUMA-R & Kumargath-RFO house & Tripura & $24^{0} 10.501$ & $92^{0} 01.922$ & 38 \\
13 & KUMA & Kumargath & Tripura & $22^{0} 09.695$ & $92^{0} 02.661$ & 39 \\
14 & FUKO & Fukirkohi & Tripura & $24^{0} 10.700$ & $92^{0} 01.288$ & 32 \\
15 & KUMA-RO & Kumargath-range office & Tripura & $24^{0} 10717$ & $92^{0} 01.923$ & 61 \\
16 & ROWA & Rowa & Tripura & $24^{0} 22.084$ & $98^{0} 49.328$ & 97 \\
17 & DI-FC & Dimapur-Forest colony & Nagaland & $25^{0} 54.733$ & $93^{0} 42.825$ & 152 \\
18 & DI-TY & Dimapur- Tykho village & Nagaland & $25^{0} 53.189$ & $93^{0} 43.271$ & 158 \\
19 & DIPU & Diphupur & Nagaland & $25^{0} 51.294$ & $93^{0} 45.493$ & 160 \\
20 & CHEK-1 & Chekieye village-1 & Nagaland & $25^{0} 51.856$ & $93^{0} 45.049$ & 162 \\
21 & CHEK-2 & Chekiye village-2 & Nagaland & $25^{0} 51.863$ & $93^{0} 45.479$ & 164 \\
22 & CHEK-3 & Chekiye village-2 & Nagaland & $25^{0} 51.871$ & $93^{0} 45.488$ & 165 \\
\hline
\end{tabular}


Randomized Block Design with 22 provenances for 3 replications. Observation with respect to survival percentage, shoot, collar diameter and numbers of branches were taken at every one month interval till the end of experiment ( 6 months) in order to, assess the suitable provenances and their survival percentage before planting in main field.

\section{Biometrical observation}

\section{Mean performance of progenies}

Survival percentage: Survival of seedlings was calculated and expressed as percentage.

$$
\text { Survival percentage }(\%)=\frac{\text { No. of survival seedling }}{\text { No. of seedlings planted in nursery }} \times 100
$$

Measurements: Shoot length, Collar diameter of individual seedlings was measured and numbers of branches was counted at an interval of one month and observation was recorded.

Variability studies: These parameters were estimated as per the method described by Johnson et al. (1955).

Phenotypic co-efficient of variability: Phenotypic Co-efficient of Variation (PCV) was arrived by using the formula as described by Burton (1952).

$\mathrm{PCV}(\%)=\frac{(\text { Phenotypic Variance })^{1 / 2}}{\text { General Mean }} \times 100$

Genotypic co-efficient of variability: Genotypic Co-efficient of Variation (GCV) was arrived by using the Burton's (1952) formula.

$\operatorname{GCV}(\%)=\frac{(\text { Genotypic Variance })^{1 / 2}}{\text { General Mean }} \times 100$

Heritability $\left(h^{2}\right)$ : Broad sense heritability $\left(h^{2}\right)$ was calculated according to Lush (1940)

$h^{2}=\left(\sigma^{2} g / \sigma^{2} p\right)$

Heritability percentage $=h^{2} \times 100$

Genetic advance: Genetic advance was worked out after Johnson et al. (1955a).

Genetic Advance $(\mathrm{GA})=[\text { (Genotypic Variance / Phenotypic Variance })^{1 / 2} \times \mathrm{K}$

Where, $K=2.06$, a selection differential at $5 \%$ selection intensity

$\mathrm{GA}(\%)=\frac{\mathrm{GA}}{\text { Grand Mean }} \times 100$

\section{Data analysis}

Biometric data for shoot length, collar diameter and number of branches were subjected to analysis of variance (Panse and Sukhatme,1978) and genetic divergence of the open pollinated families was studied following Mahalanobis $D^{2}$ (Mahalanobis, 1928) statistics. Grouping of the superior open pollinated families into various clusters was made by Tocher's method (Rao, 1952). On completion of clustering, the intra and inter cluster relationships were studied and the mutual relationship between clusters and their distances were represented. The average intra cluster distance was measured using the formula. $D^{2}=D_{1}^{2} / n$ where $D^{2}$ was the sum of the distances between all possible combinations of the open pollinated families included in a cluster whereas the average inter cluster divergence was arrived at by taking into consideration all the component $D^{2}$ values possible among the numbers of the two clusters. The genetic distance $D$ between the clusters was obtained from the square root of the average $D^{2}$ values. Estimation of genetic parameters viz., variability, PCV and GCV were computed (Burton, 1952). Heritability and genetic advance were computed (Lush, 1940; Johnson et al., 1955).

\section{RESULTS AND DISCUSSION}

\section{Mean performance of $\boldsymbol{A}$. malacansis genotypes}

Success in the establishment and the productivity of forestry plantation is governed largely by the species used and the source of seed within species (Larson, 1954; Lacaze, 1978). No matter how sophisticated the breeding techniques, the largest, cheapest and fastest gains in most forestry improvement programmes will accrue if use of suitable species and seed sources within species is assured (Zobel and Talbert, 1984). Seeds were much influenced by their place of origin (Heydecker, 1972) especially due to environmental variation in latitude, altitude, rainfall, temperature, moisture, soil and the external factors (Holzer, 1965). The seed source variations were reported on many tree species (Shivakumar and Banerjee, 1986; Murthy, 1989; Masilamani and Dharmalingam, 1999) and were dictated by environmental and edaphic factors. This might also be due to altitudinal variation (Barnett and Farmer, 1978) or region of collection (Bonner, 1984). Significant differences among provenances were detected for survival percentage. The survival rate showed a decreasing trend with decreasing latitude of provenance The survival percentage of provenance ranged from 21 (AMBS) to 42\% (NHJA and CHEK-1). The highest mean survival (42\%) was recorded in NHJA and CHEK-1 followed by UDLI-2 AND KHOW-1 (41.66\%). The provenance from AMBS-1 (21\%) followed by UDLI-1, HAKH, DI-FC and CHEK-2 (23.66\%) had lowest survival percentage (Table $3)$. In the present investigation, significant variation was observed for all the attributes viz., shoot length, collar diameter and number of branches at nursery level for 22 progenies of $A$. malacancis. Among the progenies, the superiority of three progenies viz., NHJA, KHOW-1 and CHEK-1 was evident for most of the growth characteristic investigated (Table 4). The shoot length of Agarwood provenances were observed to increase in shoot length with increase in number of days of observation. 
Table 3. Survival percentage of 22 provenance of Agar wood.

\begin{tabular}{clc}
\hline Provenance number & Provenance name & Survival percentage (\%) \\
\hline 1 & MDLY & 34.33 \\
2 & UDLI-1 & 23.66 \\
3 & UDLI-2 & 41.66 \\
4 & NHJA & 42.00 \\
5 & NHSU & 33.00 \\
6 & HAKH & 23.66 \\
7 & KHOW-1 & 42.00 \\
8 & KHOW-2 & 35.33 \\
9 & AMBS & 21.00 \\
10 & CENT-1 & 24.33 \\
11 & CENT-2 & 33.33 \\
12 & KUMA-R & 33.66 \\
13 & KUMA & 20.66 \\
14 & FUKO & 25.33 \\
15 & KUMA-RO & 31.33 \\
16 & ROWA & 32.00 \\
17 & DI-FC & 23.33 \\
18 & DI-TY & 27.33 \\
19 & DIPU & 25.00 \\
20 & CHEK-1 & 41.66 \\
21 & CHEK-2 & 23.66 \\
22 & CHEK-3 & 34.33 \\
& Mean & 30.98 \\
& SE.d & 1.483 \\
& CD (0.05) & 2.990 \\
\hline & & \\
\hline
\end{tabular}

Table 4. Morphological characters of superior genetic resources of Agarwood.

\begin{tabular}{clcccccc}
\hline $\begin{array}{c}\text { Provenance } \\
\text { number }\end{array}$ & Provenance & \multicolumn{2}{c}{ Shoot length $(\mathbf{c m})$} & \multicolumn{2}{c}{ Collar diameter $(\mathbf{m m})$} & \multicolumn{2}{c}{ Number of branches } \\
\cline { 2 - 7 } & 120 DAP & $\mathbf{1 8 0}$ DAP & $\mathbf{1 2 0}$ DAP & 180 DAP & 120 DAP & 180 DAP \\
\hline 1 & MDLY & 18.83 & 40.26 & 5.533 & 11.12 & 1.000 & 3.000 \\
2 & UDLI-1 & 21.83 & 37.93 & 5.816 & 10.70 & 1.000 & 2.000 \\
3 & UDLI-2 & 19.73 & 41.16 & 5.666 & 11.10 & 1.333 & 2.000 \\
4 & NHJA & 23.26 & 48.16 & 4.383 & 11.16 & 1.000 & 2.000 \\
5 & NHSU & 19.70 & 32.66 & 5.950 & 11.06 & 1.000 & 4.000 \\
6 & HAKH & 18.70 & 39.33 & 5.350 & 11.05 & 0.000 & 1.000 \\
7 & KHOW-1 & 24.50 & 45.00 & 5.833 & 11.12 & 0.666 & 2.000 \\
8 & KHOW-2 & 18.56 & 27.50 & 4.190 & 10.90 & 1.000 & 2.666 \\
9 & AMBS & 18.56 & 27.50 & 4.190 & 11.01 & 1.000 & 2.000 \\
10 & CENT-1 & 18.40 & 36.93 & 4.926 & 11.02 & 0.666 & 3.000 \\
11 & CENT-2 & 17.10 & 32.00 & 3.983 & 10.93 & 1.333 & 3.000 \\
12 & KUMA-R & 18.53 & 37.26 & 4.136 & 11.18 & 1.000 & 2.000 \\
13 & KUMA & 16.40 & 28.40 & 5.566 & 10.80 & 0.666 & 3.000 \\
14 & FUKO & 18.50 & 30.83 & 5.466 & 11.01 & 0.666 & 4.000 \\
15 & KUMA-RO & 16.56 & 24.00 & 6.133 & 11.03 & 0.666 & 4.000 \\
16 & ROWA & 17.90 & 30.16 & 5.433 & 11.09 & 1.333 & 3.000 \\
17 & DI-FC & 18.86 & 31.00 & 5.333 & 11.14 & 1.000 & 2.000 \\
18 & DI-TY & 20.43 & 33.56 & 5.216 & 11.10 & 0.666 & 4.000 \\
19 & DIPU & 15.73 & 25.00 & 5.600 & 11.14 & 0.666 & 3.000 \\
\hline
\end{tabular}


Table 4. Contd

\begin{tabular}{llllllll}
\hline 20 & CHEK-1 & 18.46 & 36.66 & 5.766 & 11.16 & 1.000 & 3.000 \\
21 & CHEK-2 & 17.13 & 39.23 & 5.766 & 11.26 & 0.666 & 3.000 \\
22 & CHEK-3 & 14.53 & 25.50 & 4.766 & 11.14 & 1.333 & 3.000 \\
& Mean & 18.68 & 34.47 & 5.163 & 11.05 & 0.924 & 3.030 \\
& SE.d & 1.259 & 6.117 & 0.606 & 0.158 & 0.471 & 0.864 \\
& CD $(0.05)$ & 2.537 & 12.32 & 1.222 & 0.318 & 0.950 & 1.742 \\
\hline
\end{tabular}

Table 5. Clustering pattern in Aquilaria malaccansis for morphometric attributes.

\begin{tabular}{ccl}
\hline Cluster number & Number of family & Members \\
\hline I & 3 & MDLY, NHJA, KUMA-R \\
II & 2 & NHSU, FUKO \\
III & 2 & UDLI-2, KHOW-1 \\
IV & 2 & DIPU, CHEK-3 \\
V & 4 & UDLI-1, HAKH, KHOW-2, CENT-1 \\
VI & 9 & AMBS, CENT-2, KUMA, KUMA-RO, ROWA, DI-FC, DI-TY, CHEK-1, CHEK-2 \\
\hline
\end{tabular}

Provenances only differed significantly in mean shoot length. At $120 \mathrm{DAP}$, the length of shoot varied and ranged from KHOW-1 $(24.50 \mathrm{~cm})$ to KUMA $(16.40 \mathrm{~cm})$. At $180 \mathrm{DAP}$, the provenance exhibited significant variation in shoot length ranged between NHJA (48.16 $\mathrm{cm})$ and FUKO $(30.83 \mathrm{~cm})$. NHJA $(48.16 \mathrm{~cm})$ and KHOW-1 $(47 \mathrm{~cm})$ were recorded significantly higher shoot length compared to general mean (Table 4). All other provenances were on par with general mean for this parameter.

At 120 DAP, the collar diameter ranged between NHJA $(6.133 \mathrm{~cm})$ and CENT-1 $(3.983 \mathrm{~cm})$. Other than NHJA provenance, all provenances were on par with general mean for the collar diameter. At 180 DAP, two provenance viz., NHJA $(48.16 \mathrm{~cm})$ and CHEK-1 (11.36 $\mathrm{cm}$ ) were recorded significantly higher value and UDLY-1 $(10.70 \mathrm{~cm})$ had significantly lower value compared to general mean (Table 4). The provenance HAKH (0.000) had not produced any branches and all other provenances were on par with general mean for numbers of branches at 120 DAP. At 180 DAP, number of branches varied between NHJA, KHOW-1, CHEK-1, DITY (4.000) and HAKH (1.000). HAKH (1.000) were recorded significantly lower value compared general mean (Table 4). Similarly in teak variations in several growth characters, stem and morphological characters were evident due to provenance (Rawat et al., 1998). A plethora of workers reported on the existence of variations in morphometric traits of various tree species like Dalbergia sissoo (Tewari et al., 1996), Eucalyptus tereticornis (Otegbeye, 1990), Santalum album (Bagchi and Sindu Veerendra, 1991), Tecomella undulata (Jindal et al., 1991) Lagerstroemia spp. (Jamaludheen et al., 1995) and Terminalia arjuna (Srivastava et al., 1993).

\section{Cluster composition}

Clustering methods have the goal of separating a pool of observations in many subgroups to obtain homogeneity within and between the formed subgroups. $D^{2}$ statistics is an important tool in plant breeding for estimating genetic divergence (Aslam Mohd et al., 2011). $D^{2}$ statistics is an important tool in plant breeding for estimating genetic divergence. The application of $D^{2}$ clustering technique in A. malacancis genetic resources resolved the twenty two genotypes into six clusters. Among the six clusters, the clusters $\mathrm{VI}$ and $\mathrm{V}$ were the biggest with 9 and 4 members, respectively. The Cluster I contains 3 members and remaining cluster constitutes two progeny each (Table 5 ). In Tectona grandis using $\mathrm{D}^{2}$ clustering technique 80 batches of teak had been grouped into eight clusters, of which group A formed the largest cluster containing 46 batches (Bagchi, 2000). And also, Melia dubia has been grouped into six clusters in that cluster I formed biggest group (Kumar et al., 2013). In the present investigation it was observed that the families from different locations got clubbed together to form a single major cluster as evident in cluster I and therefore the pattern of divergence was not dependent upon the geographic locations. Inclusion of geographically divergent provenances of teak in the same cluster may be attributed to the fact that the factors other than geographic distribution might be responsible for their genetic similarity (Subramanian et al., 1994).

\section{Intra and inter cluster average distance}

The intra and inter cluster analysis indicated that this may be due to introduction and demonstration during past 
Table 6. Inter and intra cluster distances for morphometric attributes.

\begin{tabular}{ccccccc}
\hline Cluster & $\mathbf{1}$ & $\mathbf{2}$ & $\mathbf{3}$ & $\mathbf{4}$ & $\mathbf{5}$ & $\mathbf{6}$ \\
\hline I & 0.48437 & 3.01125 & 0.43116 & 3.70187 & 3.29812 & 3.03829 \\
II & & 0.12625 & 4.17527 & 1.97394 & 5.21623 & 1.69394 \\
III & & & 0.19793 & 4.90531 & 2.65486 & 3.87403 \\
IV & & & & 0.22385 & 7.96942 & 2.2769 \\
V & & & & & 3.47435 & 5.64495 \\
VI & & & & & & 2.86515 \\
\hline
\end{tabular}

Table 7. Inter (diagonal) and intra cluster D2 values for morphometric attributes.

\begin{tabular}{ccccccc}
\hline Cluster & $\mathbf{1}$ & $\mathbf{2}$ & $\mathbf{3}$ & $\mathbf{4}$ & $\mathbf{5}$ & $\mathbf{6}$ \\
\hline I & 0.69597 & 1.73529 & 0.65663 & 1.92402 & 1.81607 & 1.74307 \\
II & & 0.35532 & 2.04335 & 1.40497 & 2.28391 & 1.30151 \\
III & & & 0.44489 & 2.21479 & 1.62937 & 1.96825 \\
IV & & & & 0.47313 & 2.82302 & 1.50894 \\
V & & & & & 1.86396 & 2.37591 \\
VI & & & & & & 1.69268 \\
\hline
\end{tabular}

Table 8. Percentage contributions of morphometric traits to genetic divergence at -180 DAP.

\begin{tabular}{lcc}
\hline Characters & Number of first rank & \% contribution \\
\hline Shoot length & 85 & 36.79 \\
Collar diameter & 15 & 6.493 \\
Number of branches & 131 & 56.71 \\
Total & 231 & 100 \\
\hline
\end{tabular}

years as evidenced in Bombax ceiba (Chaturvedi and Pandey, 2001). The maximum intra cluster distance was shown by the cluster II (1.803). The average intra and inter cluster $D^{2}$ and $D$ values among the six clusters are presented in Table 6 and 7. The maximum intra cluster distance was shown by the cluster $V(3.474)$ followed by cluster VI (1.692). From the inter cluster distance, it is inferred that the cluster I and III (0.484) were the closest while the maximum inter cluster distance was recorded between Cluster IV and V (7.969) which indicated the presence of wider genetic distance between $A$. malaccansis families. Such inter and intra cluster distance among Pinus gerardiana (Anilkant et al., 2006) and $M$. dubia reported which lend support to the current findings (Kumar et al., 2013).

\section{Contribution of traits towards genetic divergence}

Number of branches contributed the maximum towards genetic divergence (56.71\%) followed by shoot length(36.79\%) and the least by Collar diameter (6.493\%)
(Table 8).

\section{Variability parameters}

The assessment of genetic variability is a key to progress in tree improvement (Zobel, 1981) and is a useful tool in determining the strategies for tree improvement and breeding of any species. To understand the causes of variation, apportioning of total phenotypic variation is having more utility. The genetic variation which is heritable can be exploited for further improvement programme. In this study, number of branches registered high PCV (38.02) and GCV (15.04). Shoot length recorded moderate PCV (25.37) and GCV (14.27) followed by collar diameter PCV (1.805) and GCV (0.616) (Table 9) Higher GCV for number of branches in $E$. tereticornis and low GCV for height in the same species were earlier reported (Paramathama,1992). Similarly, low GCV and PCV for height and collar diameter were also reported in Bambusa pallida (Singh and Beniwal, 1993). The exhibition of low to moderate PCV and GCV for 
Table 9. Genetic estimates for growth attributes at 180 DAP.

\begin{tabular}{lccccc}
\hline Traits & GCV & PCV & ECV & Heritability & Genetic advance (\%) \\
\hline Shoot length & 14.27 & 25.37 & 20.98 & 0.316 & 16.54 \\
Collar diameter & 0.616 & 1.805 & 1.697 & 0.116 & 0.433 \\
Number of branches & 15.04 & 38.02 & 34.92 & 0.156 & 12.25 \\
\hline
\end{tabular}

collar diameter and shoot length in the present study is in conformity with the above assertions. The genotypic and phenotypic coefficient of variation for shoot length, collar diameter and number of branches recorded in the current study provided evidences for existence of adequate genotypic variations (Kumar et al., 2010) and thus extend the scope for exploitation of genetic variability for further improvement in this multiple utility species. The relative values of PCV and GCV give an idea about the magnitude of variability present in a genetic population. In the current study, the estimates of GCV were less than PCV for many traits indicating the role of environment in the expression of the traits. The variability parameter estimates in the study are in close approximation with the findings of genetic parameters in Azadirachta indica (Dhillon et al., 2003), Pongamia pinnata (Kumaran, 1991) and also in progenies of Dalbergia sissoo (Dogra et al., 2005) which lend support to the findings of current investigation.

\section{Heritability and genetic advances}

Heritability has an important place in tree improvement programme as it provides an index of relative strength of heredity versus environment. Dorman (1976) reported that heritability is very important in tree improvement programme. Heritability expresses the degree to which a character is influenced by heredity as compared to the environment (Kumar et al., 2010). Estimation of broad sense heritability for various characters showed low to moderate heritability for shoot length $(0.31)$, number of branches (0.15) and collar diameter (0.11) (Table 9). The results are in agreement with the studies carried out in Eucalyptus globulus who reported low heritability for $\mathrm{DBH}$ during field evaluation of 8 sub races (Apiolaza et al., 2005). Similarly, low to moderate heritability was also recorded in $E$. globulus and in Eucalyptus nitens (Raymond, 2002) for different genetic parameters and low to moderate heritability for height and tree volume in Eucalyptus grandis (Osorio et al., 2001). The authors also reported that the heritability varied with changing environment and age. Though heritability in broad sense may give useful indication about the related value of selection, heritability along with associated genetic gain should be considered together for valid, reliable and useful conclusion. In the current study, the trend of genetic advance as percent of mean was maximum in Shoot length (16.54) followed by number of branches
(12.25) and collar diameter (0.433) (Table 9) indicating a wide scope for genetic improvement in the species. The findings of current study are in line with those of Heracleum candicans (Devagiri et al., 1997). In a holistic view, the existence of adequate variability for different growth attributes coupled with low to moderate heritability indicates the possibility for identification of the best family suitable for commercial utilization.

\section{Conflict of interests}

The authors did not declare any conflict of interest.

\section{REFERENCES}

Afifi (1995). Proses pengolahan pohon gaharu sampai siap diperdagangkan dan tata cara pembudidayaannya, serta proese gaharu pembentukan gubal. In:Lokakarya Pengusahaan Hasil Hutan Non.

Anil K, Vaishnu D, Sharma DR (2006). Genetic variability in phenotypic characters of Pinus gerardiana. Indian Forester 681-690.

Apiolaza LA, Raymond CA, Yeo BJ (2005). Genetic variation of physical and chemical wood properties of Eucalyptus globulus. Silvae Genet. 42(1): 9-15.

Aslam Mohd., Zafar RA, Siddiqi TO (2011). Genetic divergence in halfsib progenies of Pinus wallichiana A.B. Jackson plus trees in the Kashmir Himalaya, India. Trop. Ecol. 52(2): 201-208.

Atal CK, Kapoor BM (1982). Cultivation and utilization of Aromatic Plants, RRL, CSIR, Jammu-Tawi, India. Augustus: 205-206.

Bagchi SK (2000). Genetic divergence in Tectona grandis. Ann. For. 8(1): 25-37.

Bagchi SK, Sindhu Veerendra HC (1991). Variation and relationship in developmental growth phases of Santalum album after pruning. Indian For. 117:1053-1058.

Barnett PE, Farmer RE (1978). Altitudinal variation in germination characteristics of yellow poplar in the Southern Appalachians. Silvae Genet. 27(3-4): 101-104.

Bonner FT (1984). Glossary of seed germination terms for Tree Seed Workers, USDA. Forest Service, Gen. Tech. Rep. Southern Forest Experiment Station, Stankville, Mississippi, USA. pp. 30-49.

Burton GW (1952). Quantitative inheritance in grass. Proc. Sixth Int. Grassland Cong. 7:277-283.

Chakrabarty K, Kumar A, Menon V (1994). Trade in Agarwood. In: Barden, A., Noorainie Awang.

Chaturvedi OP, Pandey N (2001). Genetic divergence in Bombax ceiba L. germplasms. Silvae Genet. 50:99-102.

Devagiri GM, Singh JM, Romesh Chand, Srivastava LJ (1997). Genetic variability in Heracleum candicans. Indian J. Genet. 57(3): 280-286.

Dhillon RS, Bisla SS, Arya S, Hooda MS (2003). Genetic variation, heritability and correlations for growth parameters in Azadirachta indica A. Juss. Ann. For. 11(2): 215-221.

Dogra AS, Nautiyal S, Nautiyal DP, Singh G (2005). Evaluation of field performance of 34 progenies of Dalbergia sissoo in Punjab. Ann. For. 13(2): 199-204.

Dorman KW (1976). The genetics and breeding of Southern Pines. U.S. 
Dept. of Agril. For. Serv. Agric. Handbook No. 471. p. 407.

Heydecker W (1972). Vigour. In: Viability of seeds, (ed. E.H. Roberts). Chapman Hall, London. pp. 209-252.

Holzer K (1965). Standardization of methods for provenance research and testing. Proc. of IUFRO Congress, Munchen, Germany 111(22): 672-718.

Jamaludheen V, Gopikumar K, Sudhakara K. (1995). Variability studies in Lagerstaemia (Lagerstroemia speciosa pers.). Indian For. 121(2): 137-141.

Jindal SK, Manjit Singh, Solanki KR, Kachar NL (1991). Variability and change in genetic parameter of height in juvenile progenies of Tecomella undulata (Sm.). J. Tree Sci. 10(1):25-28.

Johnson HW, Robinson HF, Comstock RE (1955). Genotypic and Phenotypic correlations on soyabean and their implications in selection. Agron. J. 47: 477-483

Johnson HW, Robinson HF, Comstock RE (1955a). Estimation of genetic and environmental variability in soy bean. Agron. J. 47: 314318.

Keller P, Sidiyasa K (1994). Trees of Balikpapan-Samarinda Area, East Kalimantan, Indonesia. In: Barden, A., Noorainie, A. A., Mulliken, T. and Song, M. (2000). Heart of the matter: Agarwood use and trade and CITES implementation for Aquilaria malaccensis. TRAFFIC International.

Kumar A, Luna RK, Parveen, Kumar V (2010). Variability in growth characteristics for different genotypes of Eucalyptus tereticornis (Sm). J. For. Res. 21(4):487-491.

Kumar P, Parthiban KT, Saravanan V (2013). Genetic Variations among Open Pollinated Families of Selected Better Trees in Melia dubia. Res. J. Recent Sci. 2:189-194.

Kumaran K (1991). Genetic analysis of seed and juvenile seedling attributes in neem (Azadirachta indica A. Juss.), pungam (Pongamia pinnata Linn. Pierre). M.Sc. Thesis, Tamil Nadu Agricultural University, Coimbatore -3 .

Lacaze JF (1978). Advances in species and provenance selection. Unasylva 30 (119-120):17-20.

Larsen CS (1954). Provenance testing and forest tree breeding proceedings. $11^{\text {th }}$ Congress, IUFRO, Rome. pp. 467-473.

Lush KI (1940). Intrasite correlation and regression of spring on dams as a method of establishing heritability of characters. Proc. Amer. Soc. Animal Production 33:293-301.

Mahalanobis PC (1928). On the generalized distance in statistics. Proceedings, National Institute of Science, India. pp. 49-55.

Masilamani P, Dharmalingam C (1999). Effect of seed treatment with hydrogen peroxide on germination and seedling vigour teak (Tectona grandis Linn.f). Trop. Agric. Res. Ext. 2:26-29.

Murthy KAVRG (1989). Observations of the variability of teak seed of different provenances. In: Seminar on provenance Research Institute of Forest Genetics and Tree Breeding, Coimbatore, January, 18-19.

$\mathrm{Ng} \mathrm{LT}$, Chang YS, Kadir AA (1997). A review on agar (gaharu) producing Aquilaria species. J. Trop. For. Prod. 2(2):272-285.

Osorio LF, White TL and Huber DA (2001). Age trends of heritability and geno-type-by-environment interactions for growth traits and wood density for clonal Eucalyptus grandis Hill ex Maiden. Silvae Genet. 50(3/4):108-117.
Otegbeye GO (1990). Provenance variation in Eucalyptus tereticornis in a field trial within the Guinea Savanna Zone of Nigeria. Silvae Genet. 39:103-107.

Panse VG, Sukhatme PV (1978). Statistical methods for agricultural workers. ICAR Publication, New Delhi.

Paramathama M (1992). Studies on genetic inheritance interspecific crosses of Eucalyptus. Ph.D. Thesis, Tamil Nadu Agricultural University, Coimbatore.

Rao CR (1952). Advanced statistical methods in biometrical research John Wiley and Sons, New York, pp. 357-363.

Rawat MS, Uniyal DP, Sharma SL (1998). Identification of provenances based on leaf morphology in Tectona grandis. Indian For. 124(4): 248-251.

Raymond CA (2002). Genetics of Eucalyptus wood properties. Ann. For Sci. 59:525-531.

Shivakumar P, Banerjee AC (1986). Provenance trials of Acacia nilotica. J. Tree Sci. 5(1):53-56.

Singh NB, Beniwal BS (1993). Variability, heritability and genetic gain of some growth characters in Bambusa balcooa. Indian For. 119(3): 205-210.

Srivastava DP, Srivastava PK, Goel AK, Thangavelu K (1993). Genetic variability in Terminalia arjuna. Indian J. For. 16: 223-225.

Subramanian KN, Nicodemus A, Radhamani A (1994). Teak improvement in India. For. Genet. Resour. 22:33-36.

Sumadiwangsa S (1997). Kayu gaharu komoditi elit di Kalimantan

Tewari SK, Kohli RK, Arya KS, Atul (1996). Diagnostic survey of shisham. Proceedings, IUFRO - DNAES International Meeting: Resource Inventory Techniques to Support Agroforestry and Environment, pp.53-55.

Vakshasya RK, Rajora OP, Rawat MS (1992). Seed and seedling traits of Dalbergia sissoo Roxb. seed source variation studies among ten sources in India. For. Ecol. Manage. 48:265-275.

Wiriadinata H (1995). Gaharu ( Aquilaria spp.) Pengembangan dan Pemanfaatan yang Berkelanjutan. In: Lokakarya Pengusahaan Hasil Hutan Non Kayu (Rotan, Gaharu, dan Tanaman Obat). Departement.

Zobel BJ (1981).Vegetative propagation in forest management operations. In: Proc, 16th South for Tree Improv, Meet, Blacksburg, Virginia.pp.149-159.

Zobel BJ, Talbert J (1984). Applied Tree Improvement. John Wiley and Co. p.505. 